\title{
Correction to: An Evaluation of Malaysian Regulatory Process for New Active Substances Approved in 2017 Using the OpERA Methodology
}

Noraisyah Mohd Sani, MSc, B. Pharmacy (Hon) ${ }^{1} \cdot$ Neil McAuslane, PhD $^{2}$. Siti Hidayah Kasbon, MSc, B. Pharmacy $(\text { Hon })^{1}$ - Rosilawati Ahmad, MSc, B. Pharmacy (Hon) ${ }^{1}$. Faridah Aryani Md. Yusof, PhD, MSc, B. Pharmacy (Hon) ${ }^{1}$. Prisha Patel, $\mathrm{MSc}^{2}$

Published online: 9 April 2020

(c) The Drug Information Association, Inc 2020

Correction to: Therapeutic Innovation \& Regulatory Science https://doi.org/10.1007/s43441-020-00140-4

The authors have revised Fig. 1. The revised Fig. 1 is presented below.

The original article can be found online at https://doi.org/10.1007/ s43441-020-00140-4.

Neil McAuslane

nmcauslane@cirsci.org

1 National Pharmaceutical Regulatory Agency, Lot 36, Jalan

Universiti, 46200 Petaling Jaya, Selangor, Malaysia

2 Centre for Innovation in Regulatory Science (CIRS), 160 Blackfriars Road, London SE18EZ, UK 


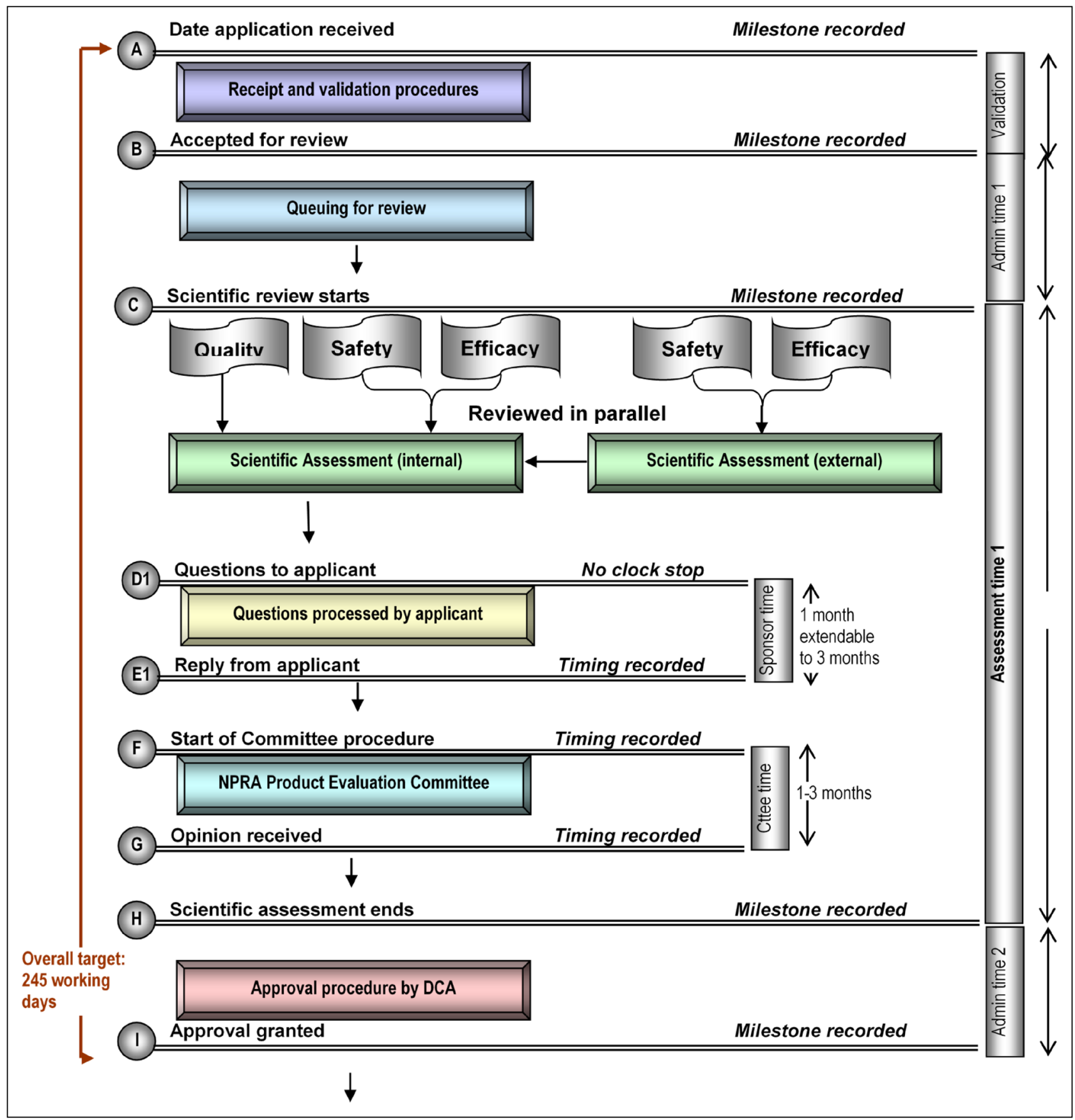

Figure 1. NPRA Review Process.

Publisher's Note Springer Nature remains neutral with regard to jurisdictional claims in published maps and institutional affiliations. 